\title{
Alveolar Macrophages in the Resolution of Inflammation, Tissue Repair, and Tolerance to Infection
}

\author{
Benoit Allard, Alice Panariti and James G. Martin*
}

Department of Medicine, Meakins Christie Laboratories, Research Institute McGill University Health Centre, McGill University, Montreal, Quebec, Canada

Pathogen persistence in the respiratory tract is an important preoccupation, and of particular relevance to infectious diseases such as tuberculosis. The equilibrium between elimination of pathogens and the magnitude of the host response is a sword of Damocles for susceptible patients. The alveolar macrophage is the first sentinel of the respiratory tree and constitutes the dominant immune cell in the steady state. This immune cell is a key player in the balance between defense against pathogens and tolerance toward innocuous stimuli. This review focuses on the role of alveolar macrophages in limiting lung tissue damage from potentially innocuous stimuli and from infections, processes

OPEN ACCESS

Edited by:

Irah L. King,

McGill University, Canada

Reviewed by:

Larry Schlesinger,

The Ohio State University,

United States

Alan L. Scott,

Johns Hopkins University,

United States

*Correspondence: James G. Martin james.martin@mcgill.ca

Specialty section:

This article was submitted to Microbial Immunology,

a section of the journal

Frontiers in Immunology

Received: 30 March 2018

Accepted: 18 July 2018

Published: 31 July 2018

Citation:

Allard B, Panariti A and Martin JG (2018) Alveolar Macrophages in the Resolution of Inflammation, Tissue Repair, and Tolerance to Infection.

Front. Immunol. 9:1777. doi: 10.3389/fimmu.2018.01777 that are relevant to appropriate tolerance of potential causes of lung disease. Notably, the different anti-inflammatory strategies employed by alveolar macrophages and lung tissue damage control are explored. These two properties, in addition to macrophage manipulation by pathogens, are discussed to explain how alveolar macrophages may drive pathogen persistence in the airways.

Keywords: disease tolerance, macrophages, tissue damage control, pathogen persistence, lung

\section{INTRODUCTION}

The lung serves the vital function of gas exchange, bringing oxygen to every single cell of the body, and disposing carbon dioxide. We inspire almost 11,000 l of air daily containing countless particles that include antigens, toxins, and microbes. It is remarkable that the lungs maintain a healthy and functional state, permitting in most instances considerable longevity. Ignoring harmless inhaled proteins, adapting to toxicants and limiting immune responses to bacteria and their cellular components are essential forms of adaptation that reduce tissue damage and that may be considered to be aspects of lung tolerance. However, while clearance of nocive inhaled substances is an optimal strategy, in some instances the host defense strategy decreases the host susceptibility to tissue damage but may permit pathogen survival. In other terms, disease tolerance is the result of the magnitude of the host reaction to the organism, which limits tissue damage but in doing so may fails to eliminate the pathogen. Here, we describe two important components leading to limiting of lung disease by alveolar macrophages (A $\varphi s$ ) by (i) repair of tissue damage and (ii) modulation of inflammation.

The $A \varphi$ is the first sentinel of the respiratory tree and constitutes the dominant immune cell in the steady state. These innate immune cells, derived from the yolk sac, are present as early as the first week after birth and are regulated in part by granulocyte-macrophage colony-stimulating factor (GM-CSF) $(1,2)$. Their niche in the alveolar space makes them important guardians of pulmonary homeostasis. A $\varphi s$ regulate the response to infections and to epithelial damage. These functions 
require the engagement of different cellular pathways, one of which is pro-inflammatory and the other trophic, requiring a range of macrophage properties that often lead to a dichotomous classification of the A $\varphi$ phenotype.

The term macrophage (from Greek: $\mu \alpha \kappa \rho u ́ c$, makros = large and $\varphi \propto \gamma \varepsilon \iota \nu$, phagein = eater) was introduced by Elie Metchnikoff in 1883, following the description of the fundamental property of phagocytosis (3). A century later, macrophages had been observed in every single organ of the body and were recognized among the first actors of innate immunity. The ultra-structure of A $\varphi s$ of mouse lung was described by Karrer (4) and the phagocytosis of India ink particles in the alveolar space by A $\varphi$ s was observed 30 min after intranasal instillation. In the steady state, Karrer also observed a large amount of ferritin within A $\varphi$ s suggesting that they ingested red blood cells. Sixty years later, the link between erythrocytes and macrophage biology has been established through the role of the heme signaling pathway in the development, differentiation, and function of macrophages (5). The most common function of A $\varphi$ s phagocytosis is the removal of apoptotic cells to ensure tissue homeostasis. Extensive work by Fadok et al. described different receptors involved in this process (6). A $\varphi s$ use different receptors such as immunoglobulin receptors and complement receptors to recognize opsonized microorganisms, facilitating their phagocytosis (7). The recognition of damage and pathogen-associated molecular patterns (DAMPs and PAMPs, respectively) by pattern recognition receptors, such as toll-like receptors or C-type lectin receptors, allows them to recognize the presence of pathogens or products of injury, and respond directly to provide optimal host protection (8). For instance, it has been recently shown that CD206 (mannose receptor) is involved in the recognition of Mycobacterium tuberculosis and the subsequent signaling (9). A $\varphi$ s are also responsible for cleaning the epithelial environment by removing "waste materials" such as oxidized lipids using scavenger receptors. Notably, expression of MARCO and class A scavenger receptors (SR-AI/II) on A $\varphi s$ is augmented so as to decrease pulmonary inflammation after oxidant inhalation (10). Finally, protection offered by pathogen recognition is complemented by enhancing the presentation of antigens to $\mathrm{T}$ cells. However, it seems that human A $\varphi$ s are less efficient in this process due to a reduced expression of B7 costimulatory cell surface molecules (11), perhaps a useful characteristic in the avoidance of an exuberant response to harmless antigens.

\section{MACROPHAGE PHENOTYPES}

The opposing properties of A $\varphi s$ designed to kill pathogens or to promote cellular proliferation and repair of tissues have been associated with supposedly discrete phenotypes termed the M1/kill and M2/repair macrophages $(12,13)$. Mills based this dichotomy on arginine metabolism: M1 can metabolize arginine to nitric oxide (and citrulline), an inhibitor of proliferation through cyclic guanosine monophosphate-dependent and -independent pathways (14), while M2 produce ornithine (and urea), a promoter of proliferation. Whether macrophages display an $\mathrm{M} 1$ or M2 profile is dependent upon the tissue environment as the tissue context may direct macrophages to provide an appropriate response (15). This plasticity results in a large spectrum of macrophage properties. In order to organize a classification of these macrophages, a consortium has published nomenclature and experimental guidelines (16).

Some of our understanding of the physiological functions of $A \varphi s$ in the lung has resulted from observing the effects of their depletion. For example, the immunosuppressive properties of A $\varphi s$ in the response to inhaled sensitizing proteins are manifested by prior depletion that results in an enhanced inflammatory response and an increased recruitment of antigenpresenting cells to regional lymph nodes and lung tissues (17). More recent studies confirm A $\varphi$ 's anti-inflammatory properties from the augmentation of inflammation in allergen challenged animals in which depletion has been induced prior to challenge $(18,19)$. Adoptive transfer of A $\varphi s$ from allergen-resistant to allergen-susceptible rats prevents allergen-induced AHR and the inflammatory cytokines interleukin-13 and tumor necrosis factor- $\alpha$ (20). These findings indicate that quiescent A $\varphi$ s have anti-inflammatory properties. A $\varphi$ s harvested from allergen challenged animals are less effective in suppressing inflammation following adoptive transfer (18). The epithelial-derived alarmins IL-33 and TSLP promote the differentiation of quiescent A $\varphi$ s to the M2 phenotype and augment macrophage-dependent allergic inflammation in the mouse $(21,22)$. Thus, A $\varphi s$ show plasticity that is dependent on the microenvironment and whereas quiescent A $\varphi$ s are predominantly immunosuppressive to avoid the development of unnecessary inflammatory responses to the host of inhaled foreign proteins encountered within the airway tree, when activated in the context of allergen challenge, the cells are less effective in their anti-inflammatory role.

\section{ALVEOLAR MACROPHAGES IN TISSUE DAMAGE CONTROL}

Whether tissue damage is of infectious or inflammatory origin, A $\varphi s$ must reduce the inflammation in first instance to limit the extent of injury. To do so, A $\varphi$ s have been described to develop different anti-inflammatory strategies (Figure 1). A $\varphi s$ are effectors of the resolution of inflammation through phagocytosis of apoptotic cells (efferocytosis), preventing dying cells from releasing proinflammatory and toxic contents into the environment while triggering the release of anti-inflammatory and repair factors (23). In vivo and in vitro studies have shown that apoptotic cell clearance induces the secretion of transforming growth factor $\beta 1$ (TGF- $\beta 1$ ), prostaglandin $\mathrm{E}_{2}\left(\mathrm{PGE}_{2}\right)$, and platelet-activating factor (PAF), with associated suppression of pro-inflammatory cytokines, chemokines, and leukotriene $\mathrm{C}_{4}$ (24-26). These findings have been confirmed in human. Indeed, defective lipopolysaccharide (LPS)-stimulated uptake of apoptotic cells by A $\varphi s$ from patients with severe asthma has been associated with failure to induce the synthesis of $\mathrm{PGE}_{2}$ and 15-hydroxyeicosatetraenoic acid (15-HETE) (27). Moreover, defective phagocytosis has been observed in several respiratory pathologies. In severe asthma in children, macrophage function is abnormal and characterized by reduced phagocytic function and excessive apoptosis (28). In addition to asthma $(27,29)$, defective phagocytic function has been described in chronic obstructive pulmonary disease (30), 


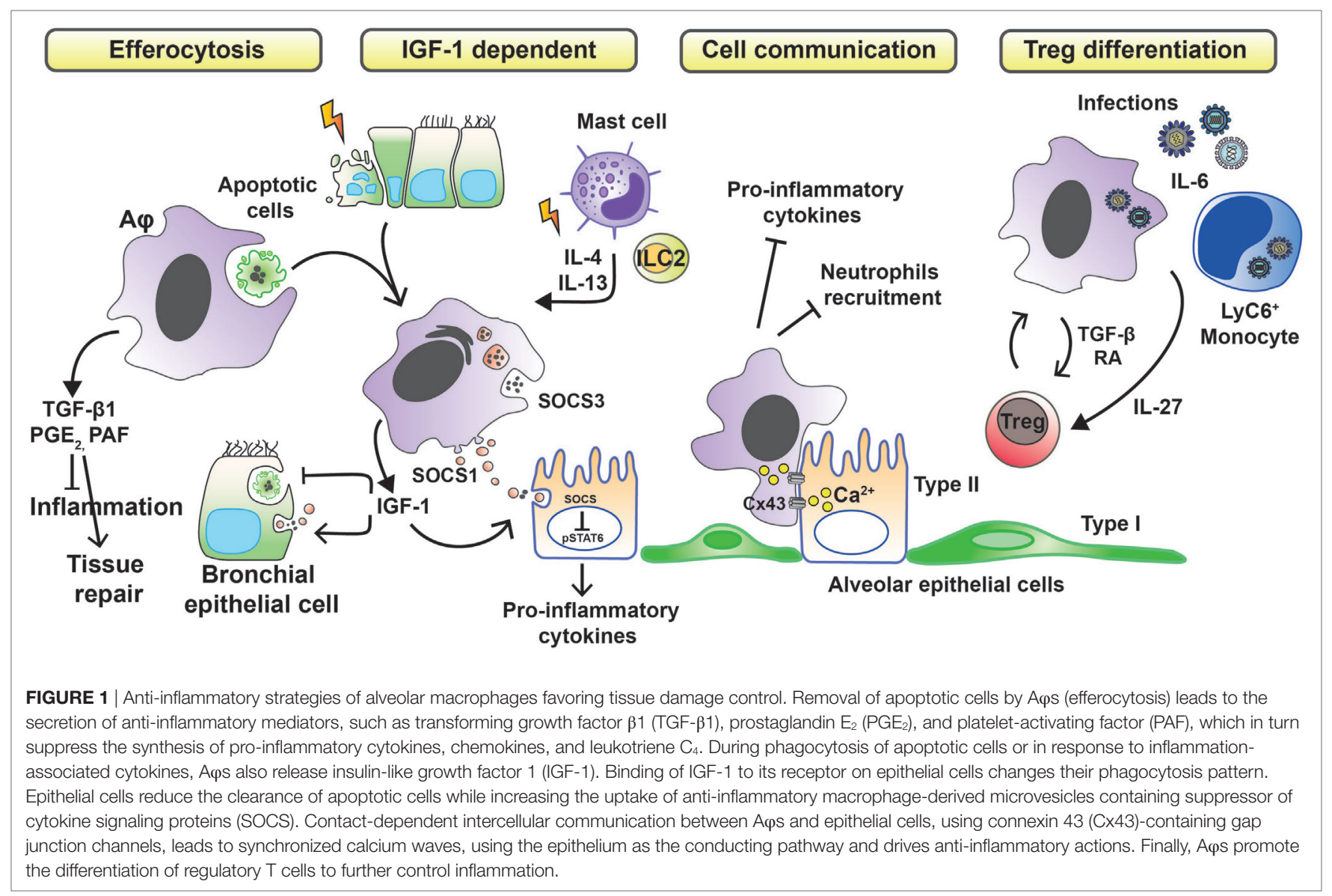

cystic fibrosis $(31,32)$, and idiopathic pulmonary fibrosis (33) and also has been attributed a role in sustained/chronic inflammation.

Allergens, such as house dust mite, can cause apoptotic epithelial cell death (34) and trigger the synthesis of IL-4 and IL-13 from mast cells and type-2 innate lymphoid cells (ILC2s). These events lead to the production of insulin-like growth factor 1 from A $\varphi$ s that enhances the uptake of anti-inflammatory macrophage-derived microvesicles by airway epithelium (35). Bourdonnay et al. report that A $\varphi$ s can secrete suppressors of cytokine signaling SOCS1 and - 3 in exosomes and microparticles, respectively, for uptake by alveolar epithelial cells and subsequent inhibition of STAT activation (36). Notably, airway epithelial cells can use $\mathrm{PGE}_{2}$ as a signal to evoke SOCS3 release from A $\varphi s$ to dampen their endogenous inflammatory responses in an LPS inflammation model (37). Contact-dependent communication between A $\varphi s$ and alveolar epithelium has been described also to modulate immunity through gap junction-like connections and the propagation of calcium waves (38). The consequence of this intercellular communication was immunosuppressive. The binding of CD200R and TGF- $\beta$ R, expressed by A $\varphi s$, with their ligands (CD200 and TGF- $\beta$, respectively) present on the cell membrane of epithelial cells is a negative regulator of A $\varphi$ activation (15).

An alternative mechanism by which A $\varphi$ s limit inflammation is through promoting a regulatory $\mathrm{T}$ cell (Treg) response. Cancer cell-activated M2-like macrophages induce activated Treg cells from $\mathrm{CD}^{+} \mathrm{CD} 25^{-} \mathrm{T}$ cells in vitro. Interestingly, the authors also demonstrated a positive-feedback loop in which activated Tregs skewed the differentiation of monocytes toward an M2-like phenotype (39). Lung tissue-resident macrophages (Siglec $\mathrm{F}^{+}$ $\mathrm{CD}_{11 \mathrm{c}^{+}}$AutoFluorescent ${ }^{\text {hi }}$, likely A $\varphi s$ ) isolated from mouse and pulsed with ovalbumin when cocultured with antigen-specific CD4 T cells result in the generation of Foxp $3^{+}$Treg cells. Treg cell induction required both TGF- $\beta$ and retinoic acid. Transfer of the antigen-pulsed tissue macrophages into the airways correspondingly prevented the development of asthmatic lung inflammation upon subsequent challenge with ovalbumin. However, other allergens, such as extracts from Dermatophagoides pteronyssinus, Aspergillus fumigatus, or cat dander, did not induce Tregs because of protease and TLR-mediated signals (40). Macrophages may also induce Tregs by an indirect pathway. Interleukin-6, a soluble mediator commonly associated with inflammation and elevated in humans with severe respiratory infection, is actually critical in promoting the resolution of the host response to respiratory viral infection and in limiting disease. Early, but not late, IL-6 signaling is required for the resolution of respiratory syncytial virus-induced immunopathology (41). Production of IL-6 after infection induces the production of the regulatory cytokine interleukin- 27 by $\mathrm{A} \varphi$ s and recruited Ly6C $\mathrm{C}^{+}$monocytes, which in turn promotes the local maturation of Treg cells. 
Since macrophages stand poised to rapidly produce large amounts of inflammatory cytokines in response to danger signals, it is logical that they are also the target of the process of resolution of inflammation. Indeed, several types of molecular controls work to downregulate the inflammatory responses of activated macrophages. These regulatory controls have been exhaustively reviewed by Mosser et al. (42). Regrettably, very few studies focused on A $\varphi s$ are referenced, suggesting a gap in this field.

Once inflammation is controlled, tissue repair must take place to restore the normal tissue architecture. In the lung, the main cells damaged by infection and inflammation are epithelial cells. As long as the injury persists, pro-inflammatory signals continue, and further damage the epithelium. Thus, the repair process may be considered an integral part of the resolution of inflammation.

Important aspects of tissue repair by macrophages have been reviewed (23). A $\varphi$ s with an M2 profile are the best candidates to orchestrate the repair of the epithelium since the metabolism of arginine to ornithine leads to cell proliferation and collagen production. Unexpectedly, M1 (or classically activated macrophages) may also participate in the lung repair by producing a large amount of amphiregulin in a mouse with LPS-induced acute lung injury (43). Amphiregulin, a ligand for the epidermal growth factor receptor, as well as other growth factors are necessary to ensure an optimal repair. A $\varphi$ s produce these growth factors to counteract the epithelial damage induced by infection. For instance, A $\varphi s$ that phagocytose apoptotic neutrophils produce hepatocyte growth factor (HGF) during bacterial pneumonia in mice (44). HGF is also produced by A $\varphi$ s to enhance alveolar epithelial proliferation during influenza infection (45). Another major growth factor, also involved in tolerogenic response, is TGF- $\beta 1$. Interestingly, macrophages that engage in efferocytosis may inhibit the TGF$\beta 1$ induced-epithelial-mesenchymal transition in lung alveolar epithelial cells via $\mathrm{PGE}_{2}, \mathrm{PGD}_{2}$, and $\mathrm{HGF}$ (46).

In studying the role of $\mathrm{A} \varphi \mathrm{s}$ in lung physiology, precautions should be taken since the population of A $\varphi s$ is heterogeneous. Indeed, monocyte-derived A $\varphi s$, recruited from the bone marrow during the inflammatory response, evoke different outcomes than resident A $\varphi s$. Monocyte-derived A $\varphi$ s recruited in response to airway epithelial-derived monocyte chemoattractant protein $1 /$ CCL2, are involved in airway inflammation and remodeling in allergic asthma (47). In a mouse model of lung injury (bleomycin and influenza A virus infection), monocyte-derived A $\varphi s$ drive lung fibrosis and persist in the lung (48). However, monocyte-derived A $\varphi$ s recruited after $\gamma$-herpesvirus (murid herpesvirus 4) infection may inhibit the development of house dust mite-induced experimental asthma (49). Thus, depending on the trigger for lung tissue damage and repair, A $\varphi s$ but also monocyte-derived A $\varphi$ s may have either beneficial or deleterious functions and more studies are required to better delineate the role of these macrophage subtypes in lung diseases.

\section{TISSUE DAMAGE CONTROL MAY DRIVE PATHOGEN PERSISTENCE}

The environment created by the tissue damage control may favor the persistence of pathogens in the airways. Indeed, the immunosuppressive properties of A $\varphi s$ during the process of the control of tissue damage are presumably key in leading to immune evasion. Evasion from immune surveillance is an important parameter leading to the persistence of pathogens (50). The incidence of methicillin-resistant Staphylococcus aureus (MRSA) pneumonia in otherwise healthy individuals is increasing (51). These bacteria persist in lower airways by surviving within A $\varphi s$. An in vitro study found that $S$. aureus persists and replicates inside a murine A $\varphi$ cell line (52). Among the mediators used by A $\varphi s$ to control tissue damage, we previously mentioned that $\mathrm{PGE}_{2}$ is produced after efferocytosis and exerts anti-inflammatory effects. $\mathrm{PGE}_{2}$ is known to suppress natural killer cell activity by increasing cellular cyclic adenosine monophosphate (53) and downregulates MHC class II expression on dendritic cells to decrease antigen presentation (54). More recently, it has been shown that the anti-inflammatory action of $\mathrm{PGE}_{2}$ in the lung is mediated only by the prostaglandin E receptor 4 (EP4) (55). In this way, it seems pathogens can take advantage of $\mathrm{PGE}_{2}$. Indeed, $\mathrm{PGE}_{2}$ can inhibit bacterial killing by A $\varphi s$ by inhibiting NADPH oxidase (56). In macrophages infected by $M$. tuberculosis, $\mathrm{PGE}_{2}$ generated by TLR2 stimulation/p38 MAPK phosphorylation triggers EP4 to produce increased amounts of $\mathrm{PGE}_{2}$. Then $\mathrm{PGE}_{2}$ provides protection against necrosis via EP2 (57). Production of $\mathrm{PGE}_{2}$ by the host is a protective mechanism against $M$. tuberculosis by inhibiting type I IFN (58) as well as inducing apoptosis in macrophages $(59,60)$. Similarly, Influenza virus induces $\mathrm{PGE}_{2}$ to suppress type I IFN subverting innate immunity (61). Taken together, it seems that pathogens have developed mechanisms to induce $\mathrm{PGE}_{2}$ production by macrophages to suppress inflammation and better survive within the host. A recent study by Roquilly et al. shows that dendritic cells and macrophages developing in the lungs after the resolution of a severe infection acquire tolerogenic properties that contribute to persistent immunosuppression and susceptibility to secondary infections (62).

$\mathrm{A} \varphi$ plasticity associated to the control of tissue damage is an important factor in pathogen persistence. The prevalence of the so-called M2 phenotype has been often associated with a positive outcome because of its ability to control tissue damage. However, M2 macrophages represent a permissive niche for the persistence of many intracellular pathogens (63). Indeed, persistence of bacteria has been described for several human diseases including Legionnaires' disease (64) and tuberculosis (65). Alarmins, such as IL-33, IL-25, and TSLP, play an important role in macrophage polarization during tissue damage (66). The synthesis of IL-33 by epithelial cells, characteristic of the lung environment after birth, triggers the release of IL-13 by ILC2s and induces an antiinflammatory M2 phenotype. Such an environment has been associated with the delayed response to Streptococcus pneumoniae infection in mice (67).

Decreased antimicrobial activity and augmented oxidative metabolism of M2 macrophages compared to glucose-dependent metabolism of M1 cells represent the main factors contributing to pathogen persistence in the host. The decreased production of nitric oxide following IL-4-driven arginase-1 expression facilitates the survival of pathogens sensitive to this reactive species (68) and perhaps explains why Chlamydia pneumoniae has been reported to prefer the M2 than M1 macrophage for its proliferation in vitro 
(69). In this scenario, pathogens not only benefit from but also drive macrophages toward the M2 phenotype that better suits their own requirements, as suggested by recent publications. A mathematical model has been proposed to facilitate the investigation of M1 to M2 switching following infection of macrophages with M. tuberculosis (70).

Mycobacterium tuberculosis upregulates the expression of peroxisome proliferator-activated receptor- $\gamma$ in infected macrophages leading to increased lipid droplet formation, expression of M2 markers and downregulation of the M1 response, including the respiratory burst and nitric oxide production (71). In this way, $M$. tuberculosis not only circumvents the protective host response but may also guarantee the nutrient rich environment required for its growth and survival. Indeed, M. tuberculosis secretes a hydrolase to catalyze host lipid hydrolysis (72). This capacity of pathogens to use cell metabolism to persist in the airspaces seems unavoidable. Further, M2 macrophages demonstrate an iron metabolism of benefit for pathogens. M2 macrophages have reduced iron storage and increased iron and heme uptake resulting in a high iron label pool (73), thus favoring the growth and survival of pathogens (63). For instance, M. tuberculosis can use macrophages as an iron source and produce siderophores able to sequester iron from host transferrin and lactoferrin, leading to augmentation of iron concentrations in infected macrophages and favoring its growth (74). Other metal metabolism can be "highjacked" by pathogens, such as zinc. Vignesh et al. have shown that IL-4, a well known M2-polarizing signals, alters macrophage zinc homeostasis via metallothionein 3 and the zinc transporter SLC30A4, promoting pathogen persistence in M2 macrophages (75).

\section{REFERENCES}

1. Guilliams M, De Kleer I, Henri S, Post S, Vanhoutte L, De Prijck S, et al. Alveolar macrophages develop from fetal monocytes that differentiate into long-lived cells in the first week of life via GM-CSF. J Exp Med (2013) 210:1977-92. doi:10.1084/jem.20131199

2. Gomez Perdiguero E, Klapproth K, Schulz C, Busch K, Azzoni E, Crozet L, et al. Tissue-resident macrophages originate from yolk-sac-derived erythromyeloid progenitors. Nature (2015) 518:547-51. doi:10.1038/nature13989

3. Kaufmann SH. Immunology's foundation: the 100-year anniversary of the nobel prize to Paul Ehrlich and Elie Metchnikoff. Nat Immunol (2008) 9:705-12. doi:10.1038/ni0708-705

4. Karrer HE. The ultrastructure of mouse lung: the alveolar macrophage. J Biophys Biochem Cytol (1958) 4:693-700. doi:10.1083/jcb.4.6.693

5. Alam MZ, Devalaraja S, Haldar M. The heme connection: linking erythrocytes and macrophage biology. Front Immunol (2017) 8:33. doi:10.3389/ fimmu.2017.00033

6. Fadok VA, Bratton DL, Henson PM. Phagocyte receptors for apoptotic cells: recognition, uptake, and consequences. J Clin Invest (2001) 108:957-62. doi:10.1172/JCI200114122

7. Fels AO, Cohn ZA. The alveolar macrophage. J Appl Physiol (1986) 60:353-69. doi:10.1152/jappl.1986.60.2.353

8. Zhang X, Mosser DM. Macrophage activation by endogenous danger signals. J Pathol (2008) 214:161-78. doi:10.1002/path.2284

9. Rajaram MVS, Arnett E, Azad AK, Guirado E, Ni B, Gerberick AD, et al. M. tuberculosis-initiated human mannose receptor signaling regulates macrophage recognition and vesicle trafficking by FcRgamma-chain, Grb2, and SHP-1. Cell Rep (2017) 21:126-40. doi:10.1016/j.celrep.2017.09.034

10. Dahl M, Bauer AK, Arredouani M, Soininen R, Tryggvason K, Kleeberger SR, et al. Protection against inhaled oxidants through scavenging of oxidized

\section{CONCLUSION}

Taken together, these studies demonstrate that A $\varphi s$ have a central place in lung disease tolerance by (i) involvement in limiting lung tissue damage from potentially innocuous stimuli (ii) decreasing immune surveillance and (iii) by hosting pathogens. Pathogen persistence in the respiratory tract is an important preoccupation, and of particular relevance to conditions such as tuberculosis. Indeed, the equilibrium between the elimination of pathogens and maintenance of tissue integrity is a sword of Damocles for susceptible patients. Better understanding of the mechanisms of disease tolerance and in the appropriate setting breaking this tolerance may provide therapeutic options. An important field requiring further exploration is the discrimination of the role of resident macrophages versus recruited macrophages in the lung environment. How recruited macrophages interfere with various functions of resident A $\varphi$ s to conserve the lung homeostasis is of great interest.

This study was funded by the Richard and Edith Strauss Canada Foundation.

\section{AUTHOR CONTRIBUTIONS}

$\mathrm{BA}, \mathrm{AP}$, and JM have written, discussed, and approved the final manuscript.

\section{FUNDING}

This study was funded by the Richard and Edith Strauss Canada Foundation.

lipids by macrophage receptors MARCO and SR-AI/II. J Clin Invest (2007) 117:757-64. doi:10.1172/JCI29968

11. Chelen CJ, Fang Y, Freeman GJ, Secrist H, Marshall JD, Hwang PT, et al. Human alveolar macrophages present antigen ineffectively due to defective expression of B7 costimulatory cell surface molecules. J Clin Invest (1995) 95:1415-21. doi:10.1172/JCI117796

12. Mills CD, Kincaid K, Alt JM, Heilman MJ, Hill AM. M-1/M-2 macrophages and the Th1/Th2 paradigm. J Immunol (2000) 164:6166-73. doi:10.4049/ jimmunol.164.12.6166

13. Mills CD. Anatomy of a discovery: M1 and M2 macrophages. Front Immunol (2015) 6:212. doi:10.3389/fimmu.2015.00212

14. Napoli C, Paolisso G, Casamassimi A, Al-Omran M, Barbieri M, Sommese L, et al. Effects of nitric oxide on cell proliferation: novel insights. J Am Coll Cardiol (2013) 62:89-95. doi:10.1016/j.jacc.2013.03.070

15. Hussell T, Bell TJ. Alveolar macrophages: plasticity in a tissue-specific context. Nat Rev Immunol (2014) 14:81-93. doi:10.1038/nri3600

16. Murray PJ, Allen JE, Biswas SK, Fisher EA, Gilroy DW, Goerdt S, et al. Macrophage activation and polarization: nomenclature and experimental guidelines. Immunity (2014) 41:14-20. doi:10.1016/j.immuni.2014.06.008

17. Thepen T, Van Rooijen N, Kraal G. Alveolar macrophage elimination in vivo is associated with an increase in pulmonary immune response in mice. J Exp Med (1989) 170:499-509. doi:10.1084/jem.170.2.499

18. Bang B-R, Chun E, Shim E-J, Lee H-S, Lee S-Y, Cho S-H, et al. Alveolar macrophages modulate allergic inflammation in a murine model of asthma. Exp Mol Med (2011) 43:275-80. doi:10.3858/emm.2011.43.5.028

19. Zasłona Z, Przybranowski S, Wilke C, van Rooijen N, Teitz-Tennenbaum S, Osterholzer JJ, et al. Resident alveolar macrophages suppress while recruited monocytes promote allergic lung inflammation in murine models of asthma. J Immunol (2014) 193:4245-53. doi:10.4049/jimmunol. 1400580 
20. Careau E, Bissonnette EY. Adoptive transfer of alveolar macrophages abrogates bronchial hyperresponsiveness. Am J Respir Cell Mol Biol (2004) 31:22-7. doi:10.1165/rcmb.2003-0229OC

21. Mizutani N, Nabe T, Yoshino S. Interleukin-33 and alveolar macrophages contribute to the mechanisms underlying the exacerbation of IgE-mediated airway inflammation and remodelling in mice. Immunology (2013) 139: 205-18. doi:10.1111/imm.12071

22. Han H, Headley MB, Xu W, Comeau MR, Zhou B, Ziegler SF. Thymic stromal lymphopoietin amplifies the differentiation of alternatively activated macrophages. J Immunol (2013) 190:904-12. doi:10.4049/jimmunol.1201808

23. Ortega-Gomez A, Perretti M, Soehnlein O. Resolution of inflammation: an integrated view. EMBO Mol Med (2013) 5:661-74. doi:10.1002/ emmm.201202382

24. Fadok VA, Bratton DL, Konowal A, Freed PW, Westcott JY, Henson PM. Macrophages that have ingested apoptotic cells in vitro inhibit proinflammatory cytokine production through autocrine/paracrine mechanisms involving TGF-beta, PGE2, and PAF. JClin Invest (1998) 101:890-8. doi:10.1172/ JCI1112

25. Huynh ML, Fadok VA, Henson PM. Phosphatidylserine-dependent ingestion of apoptotic cells promotes TGF-betal secretion and the resolution of inflammation. J Clin Invest (2002) 109:41-50. doi:10.1172/JCI0211638

26. Hoffmann PR, Kench JA, Vondracek A, Kruk E, Daleke DL, Jordan M, et al. Interaction between phosphatidylserine and the phosphatidylserine receptor inhibits immune responses in vivo. J Immunol (2005) 174:1393-404. doi:10.4049/jimmunol.174.3.1393

27. Huynh ML, Malcolm KC, Kotaru C, Tilstra JA, Westcott JY, Fadok VA, et al. Defective apoptotic cell phagocytosis attenuates prostaglandin E2 and 15-hydroxyeicosatetraenoic acid in severe asthma alveolar macrophages. Am J Respir Crit Care Med (2005) 172:972-9. doi:10.1164/rccm.200501-035OC

28. Fitzpatrick AM, Holguin F, Teague WG, Brown LA. Alveolar macrophage phagocytosis is impaired in children with poorly controlled asthma. J Allergy Clin Immunol (2008) 121:1372-8, 1378.e1-3. doi:10.1016/j.jaci.2008.03.008

29. Simpson JL, Gibson PG, Yang IA, Upham J, James A, Reynolds PN, et al. Impaired macrophage phagocytosis in non-eosinophilic asthma. Clin Exp Allergy (2013) 43:29-35. doi:10.1111/j.1365-2222.2012.04075.x

30. Hodge S, Hodge G, Scicchitano R, Reynolds PN, Holmes M. Alveolar macrophages from subjects with chronic obstructive pulmonary disease are deficient in their ability to phagocytose apoptotic airway epithelial cells. Immunol Cell Biol (2003) 81:289-96. doi:10.1046/j.1440-1711.2003.t01-1-01170.x

31. McCaslin CA, Petrusca DN, Poirier C, Serban KA, Anderson GG, Petrache I. Impact of alginate-producing Pseudomonas aeruginosa on alveolar macrophage apoptotic cell clearance. J Cyst Fibros (2015) 14:70-7. doi:10.1016/j. jcf.2014.06.009

32. Vandivier RW, Richens TR, Horstmann SA, deCathelineau AM, Ghosh M, Reynolds SD, et al. Dysfunctional cystic fibrosis transmembrane conductance regulator inhibits phagocytosis of apoptotic cells with proinflammatory consequences. Am J Physiol Lung Cell Mol Physiol (2009) 297:L677-86. doi:10.1152/ajplung.00030.2009

33. Morimoto K, Janssen WJ, Terada M. Defective efferocytosis by alveolar macrophages in IPF patients. Respir Med (2012) 106:1800-3. doi:10.1016/j. rmed.2012.08.020

34. Jyonouchi H. Airway epithelium and apoptosis. Apoptosis (1999) 4:407-17. doi:10.1023/A:1009607607603

35. Han CZ, Juncadella IJ, Kinchen JM, Buckley MW, Klibanov AL, Dryden K, et al. Macrophages redirect phagocytosis by non-professional phagocytes and influence inflammation. Nature (2016) 539:570-4. doi:10.1038/nature20141

36. Bourdonnay E, Zaslona Z, Penke LR, Speth JM, Schneider DJ, Przybranowski S, et al. Transcellular delivery of vesicular SOCS proteins from macrophages to epithelial cells blunts inflammatory signaling. J Exp Med (2015) 212:729-42. doi:10.1084/jem.20141675

37. Speth JM, Bourdonnay E, Penke LR, Mancuso P, Moore BB, Weinberg JB, et al. Alveolar epithelial cell-derived prostaglandin E2 serves as a request signal for macrophage secretion of suppressor of cytokine signaling 3 during innate inflammation. JImmunol (2016) 196:5112-20. doi:10.4049/ jimmunol.1502153

38. Westphalen K, Gusarova GA, Islam MN, Subramanian M, Cohen TS, Prince AS, et al. Sessile alveolar macrophages communicate with alveolar epithelium to modulate immunity. Nature (2014) 506:503-6. doi:10.1038/nature12902
39. Sun W, Wei FQ, Li WJ, Wei JW, Zhong H, Wen YH, et al. A positive-feedback loop between tumour infiltrating activated Treg cells and type 2-skewed macrophages is essential for progression of laryngeal squamous cell carcinoma. Br J Cancer (2017) 117(11):1631-43. doi:10.1038/bjc.2017.329

40. Soroosh P, Doherty TA, Duan W, Mehta AK, Choi H, Adams YF, et al. Lungresident tissue macrophages generate Foxp3+ regulatory $\mathrm{T}$ cells and promote airway tolerance. J Exp Med (2013) 210:775-88. doi:10.1084/jem.20121849

41. Pyle CJ, Uwadiae FI, Swieboda DP, Harker JA. Early IL-6 signalling promotes IL-27 dependent maturation of regulatory $\mathrm{T}$ cells in the lungs and resolution of viral immunopathology. PLoS Pathog (2017) 13:e1006640. doi:10.1371/ journal.ppat. 1006640

42. Hamidzadeh K, Christensen SM, Dalby E, Chandrasekaran P, Mosser DM. Macrophages and the recovery from acute and chronic inflammation. Annu Rev Physiol (2017) 79:567-92. doi:10.1146/annurev-physiol-022516-034348

43. Xu Y, Meng C, Liu G, Yang D, Fu L, Zhang M, et al. Classically activated macrophages protect against lipopolysaccharide-induced acute lung injury by expressing amphiregulin in mice. Anesthesiology (2016) 124:1086-99. doi:10.1097/ALN.0000000000001026

44. Morimoto K, Amano H, Sonoda F, Baba M, Senba M, Yoshimine H, et al. Alveolar macrophages that phagocytose apoptotic neutrophils produce hepatocyte growth factor during bacterial pneumonia in mice. Am J Respir Cell Mol Biol (2001) 24:608-15. doi:10.1165/ajrcmb.24.5.4292

45. Narasaraju T, Ng HH, Phoon MC, Chow VTK. MCP-1 antibody treatment enhances damage and impedes repair of the alveolar epithelium in influenza pneumonitis. Am J Respir Cell Mol Biol (2010) 42:732-43. doi:10.1165/ rcmb.2008-0423OC

46. Yoon YS, Lee YJ, Choi YH, Park YM, Kang JL. Macrophages programmed by apoptotic cells inhibit epithelial-mesenchymal transition in lung alveolar epithelial cells via PGE2, PGD2, and HGF. Sci Rep (2016) 6:20992. doi:10.1038/srep20992

47. Lee YG, Jeong JJ, Nyenhuis S, Berdyshev E, Chung S, Ranjan R, et al. Recruited alveolar macrophages, in response to airway epithelial-derived monocyte chemoattractant protein $1 / \mathrm{CCl} 2$, regulate airway inflammation and remodeling in allergic asthma. Am J Respir Cell Mol Biol (2015) 52:772-84. doi:10.1165/ rcmb.2014-0255OC

48. Misharin AV, Morales-Nebreda L, Reyfman PA, Cuda CM, Walter JM, McQuattie-Pimentel AC, et al. Monocyte-derived alveolar macrophages drive lung fibrosis and persist in the lung over the life span. J Exp Med (2017) 214:2387-404. doi:10.1084/jem.20162152

49. Machiels B, Dourcy M, Xiao X, Javaux J, Mesnil C, Sabatel C, et al. A gammaherpesvirus provides protection against allergic asthma by inducing the replacement of resident alveolar macrophages with regulatory monocytes. Nat Immunol (2017) 18:1310-20. doi:10.1038/ni.3857

50. Siegel SJ, Weiser JN. Mechanisms of bacterial colonization of the respiratory tract. Annu Rev Microbiol (2015) 69:425-44. doi:10.1146/annurev-micro091014-104209

51. Yajjala VK, Thomas VC, Bauer C, Scherr TD, Fischer KJ, Fey PD, et al. Resistance to acute macrophage killing promotes airway fitness of prevalent community-acquired Staphylococcus aureus strains. J Immunol (2016) 196: 4196-203. doi:10.4049/jimmunol.1600081

52. Lacoma A, Cano V, Moranta D, Regueiro V, Dominguez-Villanueva D, Laabei M, et al. Investigating intracellular persistence of Staphylococcus aureus within a murine alveolar macrophage cell line. Virulence (2017) 8:1761-75. doi:10.1080/21505594.2017.1361089

53. Goto T, Herberman RB, Maluish A, Strong DM. Cyclic AMP as a mediator of prostaglandin E-induced suppression of human natural killer cell activity. J Immunol (1983) 130:1350-5.

54. Harizi H, Juzan M, Grosset C, Rashedi M, Gualde N. Dendritic cells issued in vitro from bone marrow produce PGE(2) that contributes to the immunomodulation induced by antigen-presenting cells. Cell Immunol (2001) 209:19-28. doi:10.1006/cimm.2001.1785

55. Birrell MA, Maher SA, Dekkak B, Jones V, Wong S, Brook P, et al. Antiinflammatory effects of PGE2 in the lung: role of the EP4 receptor subtype. Thorax (2015) 70:740-7. doi:10.1136/thoraxjnl-2014-206592

56. Serezani CH, Chung J, Ballinger MN, Moore BB, Aronoff DM, PetersGolden M. Prostaglandin E2 suppresses bacterial killing in alveolar macrophages by inhibiting NADPH oxidase. Am J Respir Cell Mol Biol (2007) 37:562-70. doi:10.1165/rcmb.2007-0153OC 
57. Nishimura T, Zhao X, Gan H, Koyasu S, Remold HG. The prostaglandin E2 receptor EP4 is integral to a positive feedback loop for prostaglandin E2 production in human macrophages infected with Mycobacterium tuberculosis. FASEB J (2013) 27:3827-36. doi:10.1096/fj.13-228858

58. Mayer-Barber KD, Andrade BB, Oland SD, Amaral EP, Barber DL, Gonzales J, et al. Host-directed therapy of tuberculosis based on interleukin-1 and type I interferon crosstalk. Nature (2014) 511:99-103. doi:10.1038/nature13489

59. Divangahi M, Chen M, Gan H, Desjardins D, Hickman TT, Lee DM, et al. Mycobacterium tuberculosis evades macrophage defenses by inhibiting plasma membrane repair. Nat Immunol (2009) 10:899-906. doi:10.1038/ni.1758

60. Divangahi M, Desjardins D, Nunes-Alves C, Remold HG, Behar SM. Eicosanoid pathways regulate adaptive immunity to Mycobacterium tuberculosis. Nat Immunol (2010) 11:751-8. doi:10.1038/ni.1904

61. Coulombe F, Jaworska J, Verway M, Tzelepis F, Massoud A, Gillard J, et al. Targeted prostaglandin E2 inhibition enhances antiviral immunity through induction of type I interferon and apoptosis in macrophages. Immunity (2014) 40:554-68. doi:10.1016/j.immuni.2014.02.013

62. Roquilly A, McWilliam HEG, Jacqueline C, Tian Z, Cinotti R, Rimbert M, et al. Local modulation of antigen-presenting cell development after resolution of pneumonia induces long-term susceptibility to secondary infections. Immunity (2017) 47:135-47.e5. doi:10.1016/j.immuni.2017.06.021

63. Muraille E, Leo O, Moser M. TH1/TH2 paradigm extended: macrophage polarization as an unappreciated pathogen-driven escape mechanism? Front Immunol (2014) 5:603. doi:10.3389/fimmu.2014.00603

64. Fields BS, Benson RF, Besser RE. Legionella and Legionnaires' disease: 25 years of investigation. Clin Microbiol Rev (2002) 15:506-26. doi:10.1128/ CMR.15.3.506-526.2002

65. Smith I. Mycobacterium tuberculosis pathogenesis and molecular determinants of virulence. Clin Microbiol Rev (2003) 16:463-96. doi:10.1128/ CMR.16.3.463-496.2003

66. Hams E, Bermingham R, Fallon PG. Macrophage and innate lymphoid cell interplay in the genesis of fibrosis. Front Immunol (2015) 6:597. doi:10.3389/ fimmu.2015.00597

67. Saluzzo S, Gorki AD, Rana BMJ, Martins R, Scanlon S, Starkl P, et al. Firstbreath-induced type 2 pathways shape the lung immune environment. Cell Rep (2017) 18:1893-905. doi:10.1016/j.celrep.2017.01.071

68. Mosser DM. The many faces of macrophage activation. J Leukoc Biol (2003) 73:209-12. doi:10.1189/jlb.0602325

69. Buchacher T, Ohradanova-Repic A, Stockinger H, Fischer MB, Weber V. M2 polarization of human macrophages favors survival of the intracellular pathogen Chlamydia pneumoniae. PLoS One (2015) 10:e0143593. doi:10.1371/ journal.pone.0143593

70. Day J, Friedman A, Schlesinger LS. Modeling the immune rheostat of macrophages in the lung in response to infection. Proc Natl Acad Sci U S A (2009) 106:11246-51. doi:10.1073/pnas.0904846106

71. Rajaram MV, Brooks MN, Morris JD, Torrelles JB, Azad AK, Schlesinger LS. Mycobacterium tuberculosis activates human macrophage peroxisome proliferator-activated receptor gamma linking mannose receptor recognition to regulation of immune responses. J Immunol (2010) 185:929-42. doi:10.4049/ jimmunol.1000866

72. Singh KH, Jha B, Dwivedy A, Choudhary E, N AG, Ashraf A, et al. Characterization of a secretory hydrolase from Mycobacterium tuberculosis sheds critical insight into host lipid utilization by M. tuberculosis. J Biol Chem (2017) 292:11326-35. doi:10.1074/jbc.M117.794297

73. Recalcati S, Locati M, Marini A, Santambrogio P, Zaninotto F, De Pizzol M, et al. Differential regulation of iron homeostasis during human macrophage polarized activation. Eur J Immunol (2010) 40:824-35. doi:10.1002/ eji.200939889

74. Silva-Gomes S, Vale-Costa S, Appelberg R, Gomes MS. Iron in intracellular infection: to provide or to deprive? Front Cell Infect Microbiol (2013) 3:96. doi:10.3389/fcimb.2013.00096

75. Subramanian Vignesh K, Landero Figueroa JA, Porollo A, Divanovic S, Caruso JA, Deepe GS Jr. IL-4 induces metallothionein 3- and SLC30A4-dependent increase in intracellular $\mathrm{Zn}(2+)$ that promotes pathogen persistence in macrophages. Cell Rep (2016) 16:3232-46. doi:10.1016/j.celrep.2016.08.057

Conflict of Interest Statement: The authors declare that the research was conducted in the absence of any commercial or financial relationships that could be construed as a potential conflict of interest.

The handling Editor declared a shared affiliation, though no other collaboration, with the authors.

Copyright (c) 2018 Allard, Panariti and Martin. This is an open-access article distributed under the terms of the Creative Commons Attribution License (CC BY). The use, distribution or reproduction in other forums is permitted, provided the original author(s) and the copyright owner(s) are credited and that the original publication in this journal is cited, in accordance with accepted academic practice. No use, distribution or reproduction is permitted which does not comply with these terms. 